\title{
Volatile fatty acid production in the rumen of the grazing sheep: its use as an indicator of pasture value
}

\author{
By R. A. WELLER, A. F. PILGRIM and F. V. GRAY \\ Division of Nutritional Biochemistry, CSIRO, Adelaide, South Australia
}

(Received 4 fune I968-Accepted $_{7}$ October I968) $_{9}$

\begin{abstract}
I. An isotope dilution method, known to be satisfactory for measurement of volatile fatty acid (VFA) production in the rumen under steady-state conditions, was tested for its applicability where the VFA pool in the rumen could vary irregularly. The method indicated mean production rates closely similar to those obtained when the pool size was virtually constant. Tests carried out in a model rumen confirmed this finding and the method was accepted as suitable for measurement of VFA production in grazing sheep.

2. The method, modified to allow continuous sampling of rumen acids by dialysis, was applied to sheep grazing a mixed pasture. Mean rates of VFA production determined in seven sheep during fourteen 3 -day periods throughout winter, spring and summer months ranged from 3.4 to 5.3 moles daily, production increasing during the period of growth of the pasture, and declining again with its drying-off.

3. The pasture was at all times abundant; the findings are therefore considered to represent the pasture's full potential yield of VFA to the sheep and so to indicate its changing value in this respect as the seasons progressed.

4. Results from sheep given roughages and from the grazing sheep indicated that, despite irregular intake, good predictions of mean VFA production rates could be made from mean VFA concentrations in the rumen fluid.
\end{abstract}

The intake and digestibility of pasture by ruminants have often been studied as a basis for comparing pastures, treatments of pastures, or treatments of grazing animals.

Knowledge of volatile fatty acid (VFA) production in the rumen could usefully supplement information in this regard since these acids are the ruminant's main source of energy, and the amounts formed from any diet must be related to both the quantity consumed and its digestibility.

Recently, isotope dilution procedures for measuring VFA production in the rumen have been developed (Bergman, Reid, Murray, Brockway \& Whitelaw, 1965; Leng \& Leonard, I965; Weller, Gray, Pilgrim \& Jones, 1967) and have already been applied to grazing sheep (Leng, Corbett $\&$ Brett, I968); their complexity, however, makes this application somewhat difficult, and consequently the claim by Leng \& Brett (1966) that there is a fixed relationship between VFA concentration and VFA production in the rumen offers a desirable, because simpler, approach to field studies. Leng et al. (1968) have pointed the way to making comparisons between pastures on the basis of their potential yield of energy to sheep, by determining VFA production rates in grazing animals.

There are considerable variations in the daily intakes of pasture by sheep, and it is obvious that the mean rate of production of VFA determined over a short period such as $\mathrm{x}$ or $\mathbf{2}$ days would be unreliable as an indicator of the potential yield of VFA from the pasture. Information is needed for longer periods and from a number of animals; for the pastures to be compared fully the measurements would need to be repeated at intervals during the periods of their growth and decline. 
The relationship between concentration and production of VFA was established from isotope dilution procedures carried out in pens and in the field, but only when the pool of VFA in the rumen could be considered to be constant in size. Its application to grazing sheep for the purpose of calculating VFA production is at present based on the assumption that it would still hold good for mean concentration values obtained over long sampling periods during which the VFA pool was subject to variation in size. The work reported here provides experimental evidence in support of this assumption.

The first part of the work indicates that the isotope dilution method can be used under conditions of irregular intake of food; the second part reports changing rates of VFA production in grazing sheep during growth and decline of a pasture.

\section{EXPERIMENTAL}

\section{$V F A$ production in sheep fed at 'steady' rates}

Sheep. Four adult merino ewes $(40-45 \mathrm{~kg})$ were prepared with rumen fistulas and housed in cages fitted for measurement of VFA production.

Procedure. Each diet tested was fed in equal lots at intervals of $\mathrm{I}$ h, using the automatic feeder previously described (Gray, Weller, Pilgrim \& Jones, 1967). This type of feeding, which aims at developing a constant pool of VFA in the rumen, will be referred to as 'steady' feeding.

VFA production was determined by the isotope dilution method of Weller et al. ( $\mathrm{I} 967$ ), using a continuous infusion of $\left[\mathrm{I}-{ }^{14} \mathrm{C}\right]$ sodium acetate (approximately $0.02 \mu \mathrm{c} / \mathrm{ml}$ and $1000 \mathrm{ml} / 24 \mathrm{~h}$ ) together with continuous collection of rumen fluid over $24 \mathrm{~h}$ periods by means of an automatic sampler (Weller et al. 1967).

Diets. The diets tested, and the number of $24 \mathrm{~h}$ samples examined were: lucerne hay (26); lucerne hay pellets (25); two different mixtures of lucerne hay with wheaten hay $(4, \mathrm{II})$; lucerne hay + $50-75 \mathrm{~g} \mathrm{NaCl} /$ day $(8)$; and lucerne hay + oatmeal (8).

Analytical methods. The VFA in the rumen fluid and their content of ${ }^{14} \mathrm{C}$ were determined by methods previously described (Weller et al. 1967).

\section{$V F A$ production in sheep fed indoors at irregular rates}

Procedure. The infusion of isotope, sampling of rumen fluid, and analytical procedures used above, were applied to the sheep when fodder was given at irregular rates, in two types of feeding regime.

(I) Two sheep were fed at controlled rates which changed both within and between days in accordance with the general pattern shown in Fig. I. Two diets were employed, one lucerne hay (batch LH I) and the other a mixture of lucerne hay with wheaten hay. Total sampling periods were 7 days and 8 days respectively. These diets had already been tested under steady feeding conditions.

(2) Two sheep were fed lucerne hay (batch LH 2) only once a day and were given widely different amounts on successive days, the quantities varying from about 200 to $1100 \mathrm{~g}$ dry weight. Here the total sampling times were 12 days and 8 days, made up of groups of 4 days of continuous sampling. This batch of lucerne hay was also tested under steady feeding conditions. 


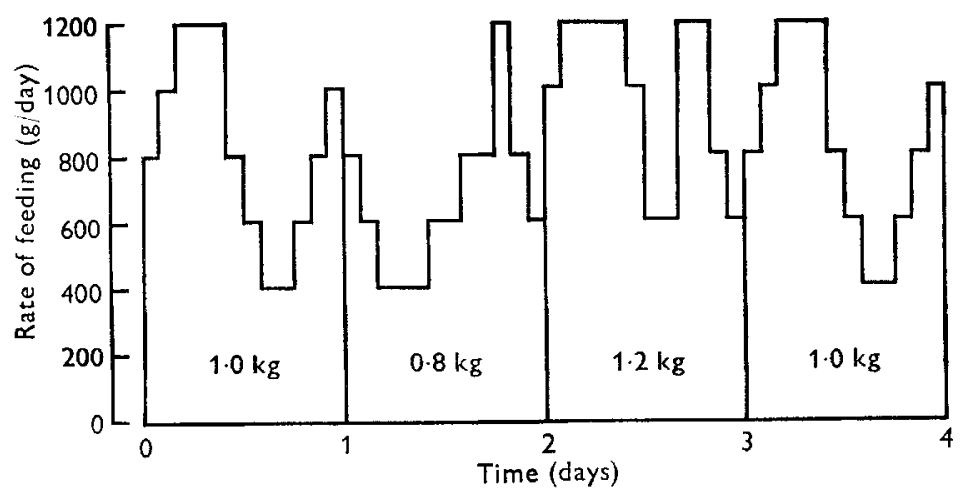

Fig. I. Pattern of irregular feeding imposed on sheep, showing variation of intake within and between days.

\section{A further test of the validity of the isotope dilution procedure: use of an equivalent marker procedure in a model rumen}

In order to make a further check on the use of the isotope dilution method when the VFA pool size is not constant (as with irregular feeding), a model rumen, similar to one described earlier, was set up. The earlier model (Gray, Weller, Pilgrim \& Jones, rg66) made use of pure solutions of VFA and included ${ }^{14} \mathrm{C}$-labelled VFA as marker. In the model reported here a solution of calcium and magnesium salts represented the amounts of VFA and ${ }^{14} \mathrm{C}$-labelled VFA respectively in the rumen fluid. Introduction and removal of these two substances and of water were so arranged that varying rates of entry of VFA, changes in rumen volume, changes in VFA concentrations, and the constant rate of infusion of labelled VFA could be simulated. In these circumstances a close check was made on the validity of the isotope dilution method when used under conditions considered to be similar to those that occur or may occur in the rumen of the grazing sheep.

Apparatus and procedure. A vessel representing the rumen contained at the start about $200 \mathrm{ml}$ of a solution of $\mathrm{CaCl}_{2}$ (Ca representing total VFA) and $\mathrm{MgCl}_{2}(\mathrm{Mg}$ representing ${ }^{14} \mathrm{C}$-labelled VFA). A variable output pump was used for adding further $\mathrm{CaCl}_{2}$ at varying rates. $\mathrm{MgCl}_{2}$ was introduced at a constant rate. The volume of the 'rumen' fluid was varied by changing the inflow and outflow of water, these again being controlled by variable output pumps. Variation in the flow of water through the 'rumen' also allowed control of the rate of removal of $\mathrm{Ca}$ and $\mathrm{Mg}$ from the system. A period of 120 min was used to represent I day, and within each of Io such 'days' the volume in the 'rumen', and the entry rate of Ca were varied in ways considered to be similar to those that could occur in the volume and VFA entry rate for the rumen in grazing sheep. The contents of the vessel were stirred continuously and samples were taken at 5 min intervals as fluid left the 'rumen'. This method of sampling did not correspond precisely to that used in the trials with caged sheep or to the method to be described for grazing sheep, where sampling of rumen acids was virtually continuous. Nevertheless, the mean values for concentration of $\mathrm{Ca}$ and $\mathrm{Mg}$ each 'day' would be similar to those obtained by continuous sampling. 
Details of starting concentrations and variations imposed on 'rumen' volume and Ca entry rates can be seen in Fig. $2(a)$. This together with Fig. $2(b)$ shows how the model did in fact test application of the principles involved in the isotope dilution method under conditions where the pool size varied markedly and irregularly.

Analytical methods. The $\mathrm{Ca}$ and $\mathrm{Mg}$ concentrations were determined by atomic absorption.

\section{Recycling of absorbed ${ }^{14} \mathrm{C}$ during prolonged infusion of ${ }^{14} C$-labelled VFA into the rumen}

It has been suggested (Leng et al. ${ }^{1968)}$ that the amount of ${ }^{14} \mathrm{C}$ returned to the rumen after absorption might lead to significant errors in the type of procedure used for the VFA production trials described above.

In one of the sheep previously used, a continuous infusion of ${ }^{14} \mathrm{C}$-labelled sodium acetate was given into the external jugular vein. The infusion consisted of $500 \mathrm{ml} / \mathrm{day}$ of a solution containing $\left[\mathrm{I}^{14} \mathrm{C}\right]$ sodium acetate $(0.05 \mu \mathrm{c} / \mathrm{ml})$, for a period of 3 days-a rate of infusion equivalent to that used for ${ }^{14} \mathrm{C}$-labelled VFA into the rumen. Continuous sampling of rumen fluid began on the 2nd day, to give composite samples of fluid for each of the final 2 days. These samples were analysed in the way described for those in the VFA production trials.

\section{VFA production in grazing sheep}

Animals and pasture. Seven Merino ewes, all approximately $2 \cdot 75$ years of age and with weights ranging from 35 to $54 \mathrm{~kg}$ were prepared with small rumen fistulas, fitted with soft polyvinyl chloride cannulas. The sheep grazed a 3.5 acre paddock of mixed pasture throughout the winter, spring and summer months of 1967 .

Following the winter rains at the end of June there was a good growth of mixed pasture, mainly brome grasses (Bromus spp) and ryegrass (Lolium sp) with patches of Phalaris tuberosa being preferentially grazed. From August to the end of October barley grass (Hordeum $\mathrm{sp}$ ) became dominant, with a good undercover of subterranean clover (Trifolium subterraneum) and Medicago spp.

At the end of September the paddock was 'topped' to delay heading and improve the quality of the late pasture. Drying off began about mid-October and was complete after approximately 6 weeks. At the end of November there was a good cover of standing dry feed containing mainly barley grass, brome grasses and patches of ryegrass; the clover and medic had by then dried and broken up.

Field procedures. Each animal wore a harness which carried two aluminium boxes. From one of these a continuous infusion of $\left[\mathrm{I}^{14} \mathrm{C}\right]$ sodium acetate $(0.125 \mu \mathrm{c} / \mathrm{ml}, 0.02 \mathrm{~g}$ of carrier acetate $/ \mathrm{ml}$ ) was given into the rumen by means of a clock-driven syringe at a uniform rate of $20 \mathrm{ml} / 24 \mathrm{~h}$. From the other a similar syringe maintained a constant flow of saline $(0.9 \% \mathrm{NaCl} ; 20 \mathrm{ml} / 24 \mathrm{~h})$ through a dialysing cell lodged in the rumen, and the dialysate containing rumen VFA was passed from the rumen to be collected in a small rubber bag. The principles of this procedure and apparatus have been described earlier (Gray et al. 1967). Modifications introduced during the work reported here included the substitution of silicone rubber o-rings in the syringes and an increase in the length of the probe and its Visking dialysis tubing to $4.5 \mathrm{~cm}$. 
During the trials infusion began $24 \mathrm{~h}$ before the start of the sampling periods. Samples were removed and the syringes recharged at the same time each day.

Because of the gradual attack on the dialysis membrane by rumen micro-organisms the complete probe assembly was replaced after 2 days in the rumen although tests showed that it could remain effective for longer periods.

Variations within and between sheep in their daily intake of pasture made it necessary to consider the mean production rate for a number of sheep over a period of several days if this rate was to be indicative of the 'value' of the pasture at that time. It was decided that a total sampling time of not less than $240 \mathrm{~h}$ divided among as many as possible of the seven sheep available, would be acceptable. Samples were therefore collected for 3 successive days in each of fourteen separate periods during the 7 months from June to December. Technical difficulties associated with the use of the apparatus under field conditions led to faulty runs at times, but these became much fewer in the later stages of the experiment. Two early periods yielded only six and eight lots of $24 \mathrm{~h}$ samples in the 3 -day periods, but no other period yielded less than ten.

The sheep were weighed at intervals during the experiment and rainfall was recorded regularly.

Analytical methods. Samples of the dialysates were analysed for VFA and their ${ }^{14} \mathrm{C}$ content in the same way as rumen fluid samples, and the mean rate of production (m-moles VFA/min) during the 3-day period was obtained as the mean value for the quotients

$$
\begin{aligned}
& { }^{14} \mathrm{C} \text { infused }(\mu \mathrm{c} / \mathrm{min}) \\
& { }^{14} \mathrm{C} \text { in VFA of dialysate }(\mu \mathrm{c} / \mathrm{m} \text {-mole })
\end{aligned}
$$

in all the $24 \mathrm{~h}$ samples collected during that time. During some of the periods individual acids in the rumen VFA mixture were determined by methods previously described (see Gray et al. 1967); in others only the total VFA was considered.

\section{Time spent grazing}

At the end of the grazing period described above, two of the sheep were used for telemetric recording of jaw movements so that estimates could be made of the time they spent grazing during the day. A harness of elastic webbing attached to the animal's head held a micro-switch operated by movements of the lower jaw. The switch operated a small radio transmitter, of the type used for model aircraft control, carried on the sheep's back. A receiver with inbuilt relay was connected to a chart recorder and the circuit adjusted so that an impulse of $1.5 \mathrm{sec}$ produced a full excursion of the recording pen. The receiver and recorder were located near the centre of the 3.5 acre paddock where the test animals grazed with a small group of sheep. Recordings were made for $24 \mathrm{~h}$ periods at a chart speed of $\mathrm{I} \mathrm{ft} / \mathrm{h}$. Patterns produced by grazing, ruminating and resting were quite distinctive and total grazing time was measured directly from the chart (Pl. I). One sheep was examined for 4 consecutive days, and the other for five periods of 3 consecutive days within a period of I month. 


\section{Comparison of VFA concentration in rumen fluid and dialysate}

The concentrations of VFA in the dialysates were not equal to the corresponding mean VFA concentrations in the rumen fluid itself. Tests were therefore conducted in which sampling of the rumen acids by dialysis was compared with direct sampling of the rumen fluid using the automatic, continuous sampler described by Weller et al. ( 1967 ). Both methods were applied to the same sheep at the same time for periods of $24 \mathrm{~h}$. Since the apparatus could not be used with animals under natural grazing conditions, the tests were made on sheep fed on lucerne hay; two sheep were fed at irregular rates and one at a steady rate. The total sampling time was $240 \mathrm{~h}$.

\section{RESULTS}

Comparisons of VFA production in sheep fed at steady and irregular rates

The validity of the isotope dilution method when used under conditions of irregular intake was tested by comparing the yield of VFA from unit weight of fodder subjected to the rumen fermentation (i.e. passing through the rumen to the omasum) with the

Table I. Production of VFA in the rumen of sheep during irregular and steady feeding

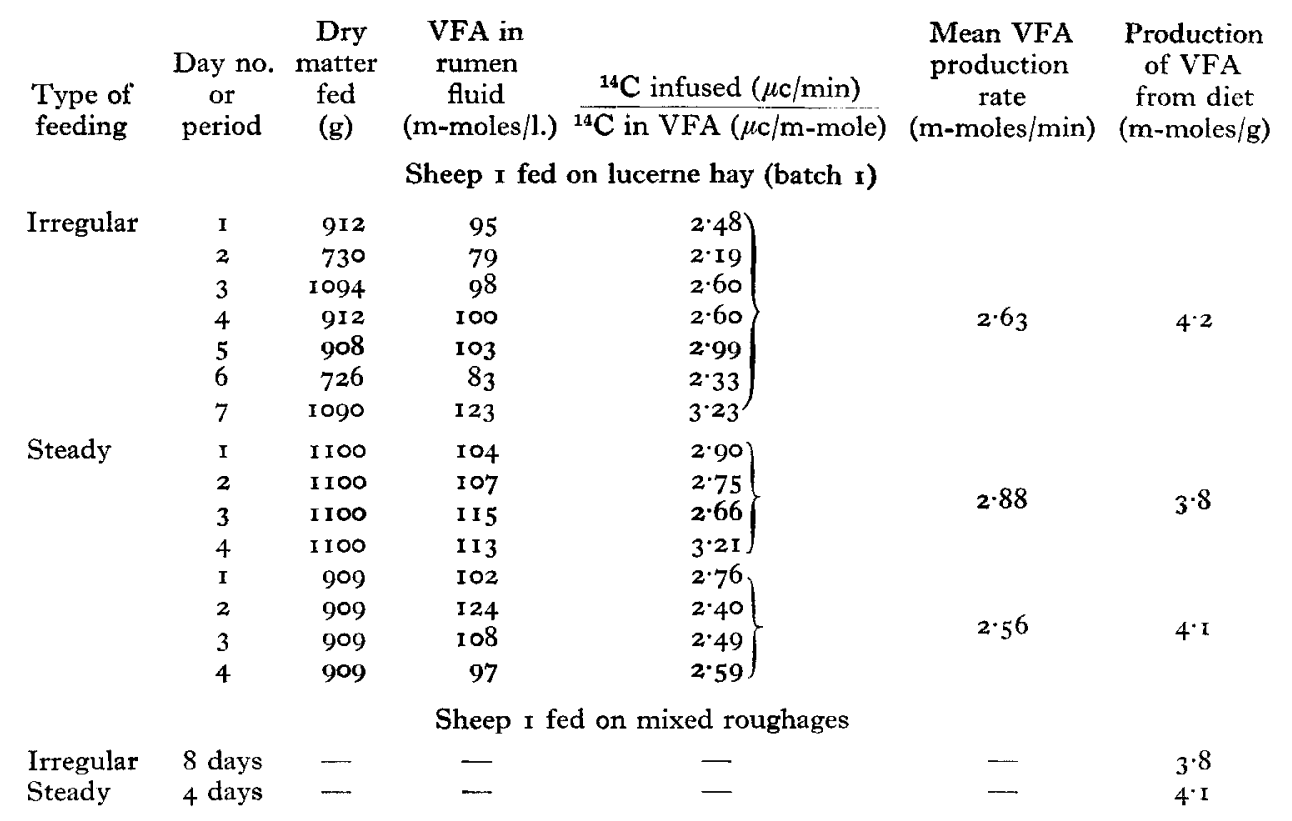

corresponding yield under steady intake conditions, i.e. when the VFA pool in the rumen was constant and it was known that the method was applicable.

Results for one sheep fed on lucerne hay (batch $\mathrm{I}$ ) at steady rates and at rates which were changed within and between days (Fig. I) are given in full in Table 1 , and results from the same sheep, fed on mixed roughages, are also summarized there. It is evident that similar amounts of VFA were calculated to be produced from unit weights of these fodders whether they were fed at steady or irregular rates. 
Table 2 gives the results in full for one of the sheep fed on lucerne hay (batch 2) once daily and for the same fodder fed at a steady rate. Results from a second sheep are summarized in the same Table. Here again it is evident that similar amounts of VFA were calculated to be formed from unit weight of the fodder whether it was fed steadily or irregularly.

These findings support the view that the method is applicable under conditions of irregular intake of food.

Table 2. Production of VFA in the rumen of sheep during irregular and steady feeding (lucerne hay, batch 2)

\begin{tabular}{|c|c|c|c|c|c|c|}
\hline $\begin{array}{l}\text { Type of } \\
\text { feeding }\end{array}$ & $\begin{array}{l}\text { Day no. } \\
\text { or } \\
\text { period }\end{array}$ & $\begin{array}{l}\text { Dry } \\
\text { matter } \\
\text { fed } \\
(\mathrm{g})\end{array}$ & $\begin{array}{l}\text { VFA in } \\
\text { rumen } \\
\text { fluid } \\
\text { (m-moles/l.) }\end{array}$ & $\frac{{ }^{14} \mathrm{C} \text { infused }(\mu \mathrm{c} / \mathrm{min})}{{ }^{14} \mathrm{C} \text { in VFA }(\mu \mathrm{c} / \mathrm{m}-\mathrm{mole})}$ & $\begin{array}{l}\text { Mean VFA } \\
\text { production } \\
\text { rate } \\
\text { (m-moles } / \text { min) }\end{array}$ & $\begin{array}{l}\text { Production } \\
\text { of VFA } \\
\text { from diet } \\
\text { (m-moles } / g \text { ) }\end{array}$ \\
\hline \multicolumn{7}{|c|}{ Sheep I } \\
\hline \multirow[t]{12}{*}{ Irregular } & $\mathbf{I}$ & 507 & 87 & 2.57 & \multirow{12}{*}{$2 \cdot 60$} & \multirow{12}{*}{$5 \cdot 4$} \\
\hline & 2 & 635 & 82 & $2 \cdot 01$ & & \\
\hline & 3 & 1100 & 123 & $3 \cdot 64$ & & \\
\hline & 4 & 967 & 124 & $3 \cdot 57$ & & \\
\hline & I & 533 & 75 & $2 \cdot 30$ & & \\
\hline & 2 & 644 & 81 & 2.50 & & \\
\hline & 3 & 196 & 47 & $1 \cdot 20$ & & \\
\hline & 4 & 309 & 59 & $x \cdot 24$ & & \\
\hline & I & I I 6 & II 3 & 3.48 & & \\
\hline & 2 & 977 & 117 & 3.80 & & \\
\hline & 3 & 577 & 86 & $2 \cdot 4 \mathrm{I}$ & & \\
\hline & 4 & 725 & 90 & $2 \cdot 50$ & & \\
\hline \multirow[t]{8}{*}{ Steady } & I & 912 & 97 & 3.64 & \multirow{5}{*}{3.60} & \multirow{4}{*}{$5 \cdot 7$} \\
\hline & 2 & 912 & 98 & $3 \cdot 34$ & & \\
\hline & 3 & 912 & 99 & $3 \cdot 75$ & & \\
\hline & 4 & 912 & 95 & 3.65 & & \\
\hline & I & 914 & 97 & $3.50)$ & & \multirow{4}{*}{$5 \cdot 6$} \\
\hline & 2 & 914 & 98 & $3 \cdot 81$ & \multirow{3}{*}{$3 \cdot 53$} & \\
\hline & 3 & 914 & 97 & $3.42\}$ & & \\
\hline & 4 & 914 & 98 & 3.401 & & \\
\hline
\end{tabular}

Sheep 2

$\begin{array}{lllllll}\text { Irregular } & 8 \text { days } & - & - & - & - & 5 \cdot 0 \\ \text { Steady } & 4 \text { days } & - & - & - & - & 5.0 \\ & 4 \text { days } & - & - & - & - & 5.5\end{array}$

\section{Model rumen experiment}

Values presented in Fig. 2(b) make it possible to follow the progressive changes in the concentrations of $\mathrm{Ca}$ and $\mathrm{Mg}$ and also changes in the size of the $\mathrm{Ca}$ pool. The concentration of $\mathrm{Ca}$ varied from 40 to $180 \mathrm{mg} / \mathrm{l}$. and the $\mathrm{Ca}$ pool from 10 to $45 \mathrm{mg} \mathrm{Ca}$. The relationships between $\mathrm{Ca}$ entry rate, $\mathrm{Ca}$ concentration, and $\mathrm{Ca}$ pool size were similar to, or extended beyond, the corresponding relationships likely to be found for VFA in the rumen.

Table 3 summarizes the results obtained when the amounts of $\mathrm{Ca}$ added to the 'rumen' were calculated from the equation

$$
\mathrm{Ca} \text { added }(\mathrm{mg})=\frac{\mathrm{Mg} \text { added }(\mathrm{mg})}{\mathrm{Mg}(\mathrm{mg}) / \mathrm{Ca}(\mathrm{mg}) \text { in 'rumen' fluid }} .
$$


Even the amounts calculated to have been added each 'day' show relatively small differences from those actually introduced. When extended sampling periods were examined to obtain a mean $\mathrm{Mg}$ to $\mathrm{Ca}$ ratio, the error in the calculated $\mathrm{Ca}$ added was less than $5 \%$.

These findings again support the view that an isotope dilution method would be applicable under conditions of irregular intake of food by sheep.
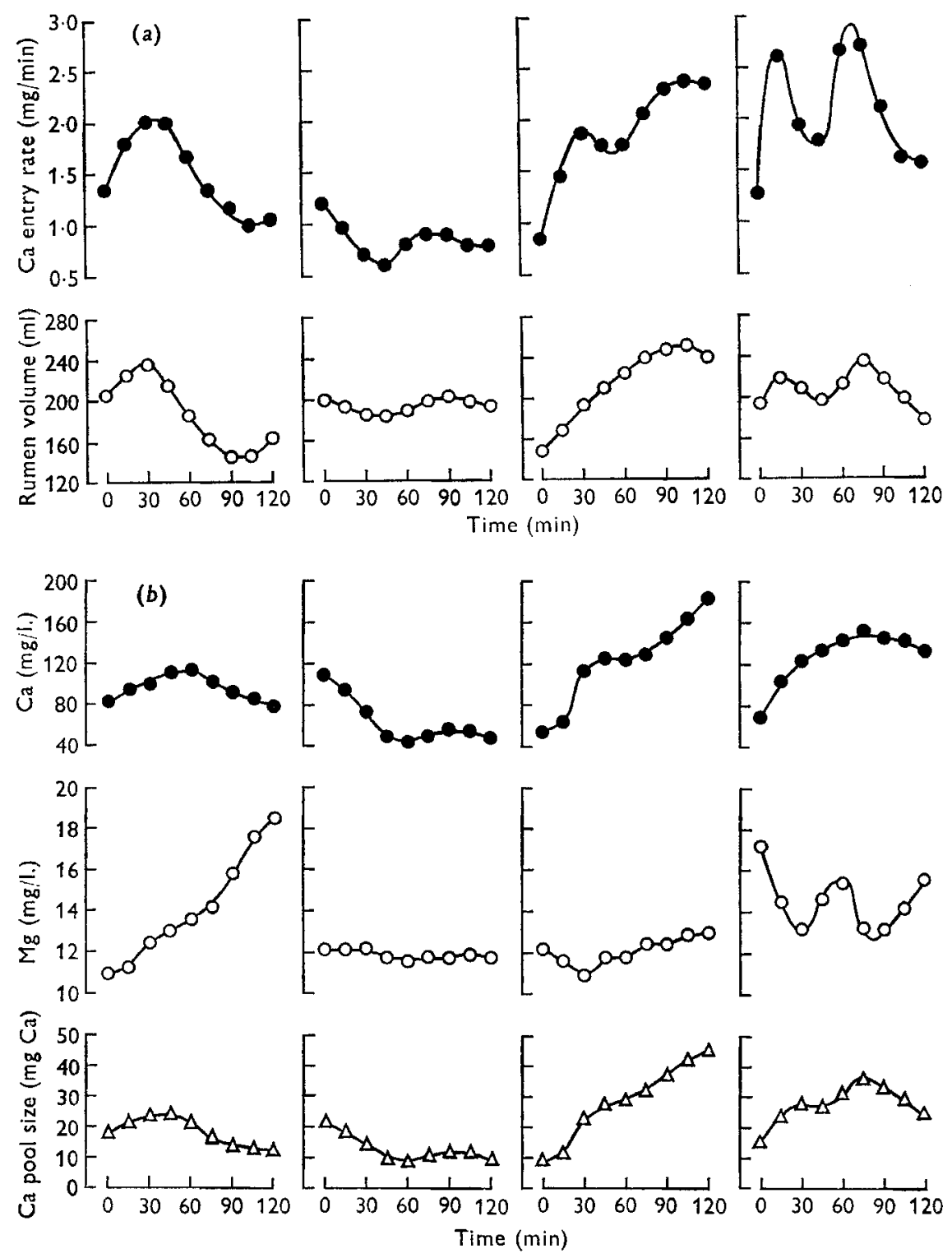

Fig. 2. Conditions in the model rumen. Values represent $15 \mathrm{~min}$ intervals. (a) Calcium entry rates and 'rumen' volume during four of the ten periods. (b) Calcium and magnesium concent rations in 'rumen' fluid, and calcium pool size. 


\section{Recycling of absorbed ${ }^{14} C$ during prolonged infusion of ${ }^{14} C$-labelled VFA into the rumen}

The concentration of ${ }^{14} \mathrm{C}$ in the fatty acids of the rumen fluid during infusion of ${ }^{14} \mathrm{C}$ into the blood stream was found to be only a small proportion of that usually observed when similar quantities are infused into the rumen of sheep fed in the same manner, namely, less than $6 \%$ on both the 2 nd and 3 rd days of the experiment. This small degree of recycling, if it occurred in trials for measuring VFA production, would tend

Table 3. Model rumen: calcium entry rates into the 'rumen'

Sampling period-I 'day'*

\begin{tabular}{|c|c|c|c|c|c|c|c|c|c|}
\hline ‘Day’’ & I & 2 & 3 & 4 & 5 & 6 & 7 & 8 & 9 \\
\hline $\mathrm{Ca}$ added (mg) & 197 & 285 & 240 & 118 & 273 & I 80 & 270 & 232 & I I I \\
\hline Ca determined (mg) & 2 I 3 & 275 & 271 & 135 & 273 & 175 & 221 & 242 & 121 \\
\hline Error $(\%)$ & 8 & -4 & I3 & I 4 & 0 & -3 & -18 & 4 & 10 \\
\hline \multicolumn{10}{|c|}{ Extended sampling periods -2 'days' to Io 'days' } \\
\hline 'Days' & $1-2$ & $I-3$ & $1-4$ & $I-5$ & $I-6$ & $\mathrm{I}-7$ & $\mathrm{I}-8$ & $I-9$ & $1-10$ \\
\hline $\mathrm{Ca}$ added $(\mathrm{mg})$ & 482 & 722 & 840 & III 3 & 1293 & 1563 & 1795 & 1006 & $2 \times 63$ \\
\hline Ca determined (mg) & 488 & 759 & 884 & I I 57 & 1332 & I553 & 1795 & 1916 & 2163 \\
\hline Error $(\%)$ & $\mathbf{I}$ & 5 & 5 & 4 & 3 & I & 0 & I & 0 \\
\hline
\end{tabular}

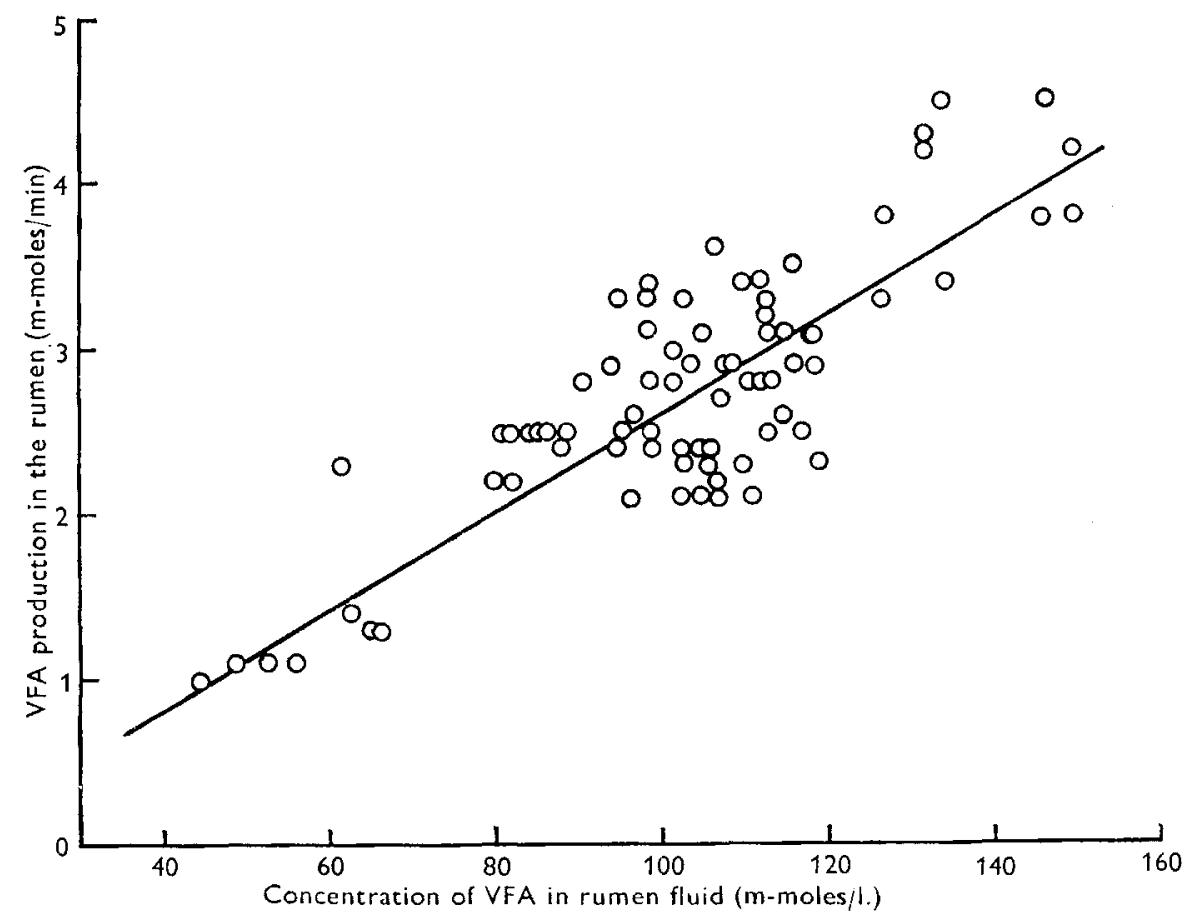

Fig. 3. Relationship between VFA concentration and VFA production in the rumen, measured by an isotope dilution method, in sheep fed at 'steady' rates. 
to counterbalance the small loss of ${ }^{14} \mathrm{C}$ that may occur from labelled VFA in the rumen (see Gray et al. I966). No correction has been made for this effect in the work reported here.

\section{Relationship between VFA concentration and VFA production in the rumen of sheep fed at steady rates}

Results from the trials are shown in Fig. 3, where VFA concentrations in the rumen fluid are plotted against VFA production rates determined by isotope dilution. Statistical analysis led to the regression equation

$$
y=-0.296+0.02927 x
$$

where $x=$ VFA concentration in rumen fluid (m-moles/1.) and $y=$ VFA production in the rumen $(\mathrm{m}-\mathrm{moles} / \mathrm{min})$. Residual SD $=0.414 \mathrm{~m}-\mathrm{moles} / \mathrm{min}$ and SE of regression coefficient $=0.002 \mathrm{I} 7$.

\section{Time spent grazing}

During the 19 days examined, grazing time ranged from 3.4 to $7.6 \mathrm{~h}$ daily (mean $5.2 \mathrm{~h}$ ). For the 4 consecutive days with one sheep the range was $3 \cdot 4-6.4 \mathrm{~h}$, and in the five periods of 3 consecutive days for the other sheep it was $3 \cdot 7-7 \cdot 6 \mathrm{~h}$.

Variation in grazing time was therefore considerable and it is reasonable to conclude that variation in intake could be of the same order. It will be noted that this variation was not so great as that imposed on the intakes in the second type of irregular feeding examined in the caged sheep.

\section{VFA production in grazing sheep}

Table 4 lists the mean production rates (m-moles/min and moles/day) determined by isotope dilution at intervals throughout a period of 7 months, and Fig. 4 summarizes the findings in this section of the work. Values of two determinations made in June are included in Table 4 although it is doubtful whether the total sampling times

Table 4. Production of VFA in the rumen of grazing sheep

\begin{tabular}{|c|c|c|c|c|c|c|}
\hline \multirow[b]{2}{*}{ Date } & \multirow[b]{2}{*}{$\begin{array}{l}\text { No. of } \\
\text { sheep } \\
\text { sampled }\end{array}$} & \multirow[b]{2}{*}{$\begin{array}{c}\text { No. of } \\
24 \mathrm{~h} \\
\text { samples }\end{array}$} & \multirow{2}{*}{$\begin{array}{c}\text { Mean VFA } \\
\text { concentration } \\
\text { in } \\
\text { rumen fluid } \\
(\mathrm{m} \text {-moles } / 1 .)\end{array}$} & \multicolumn{3}{|c|}{ Estimated mean production rate } \\
\hline & & & & $\begin{array}{r}\text { isoto } \\
\text { m-moles } /\end{array}$ & $\begin{array}{l}\text { ion } \\
\text { les/day }\end{array}$ & $\begin{array}{c}\text { From VFA } \\
\text { concentration } \\
\text { (moles/day) }\end{array}$ \\
\hline 8-9 June & 4 & 6 & I 18 & $3 \cdot 3$ & $4 \cdot 6$ & 4.5 \\
\hline 22-23 June & 5 & 8 & 101 & $2 \cdot 4$ & $3 \cdot 3$ & $3 \cdot 8$ \\
\hline 5-7 July & 6 & II & 112 & $3 \cdot 2$ & $4 \cdot 4$ & $4 \cdot 3$ \\
\hline 2-4 Aug. & 5 & I5 & 108 & $3 \cdot 4$ & $4 \cdot 4$ & $4^{*} \mathrm{I}$ \\
\hline 16-18 Aug. & 5 & 12 & 136 & $3 \% 7$ & $5 \cdot 1$ & $5 \cdot 3$ \\
\hline 23-25 Aug. & 6 & 16 & 128 & $3: 7$ & $5 \cdot 2$ & $5 \cdot 0$ \\
\hline 6-8 Sept. & 6 & 14 & 126 & $3 \cdot 2$ & $4 \cdot 4$ & $4 \cdot 9$ \\
\hline 20-22 Sept. & 7 & I8 & II 7 & 3.6 & $5 \cdot 2$ & $4 \cdot 5$ \\
\hline 4-6 Oct. & 7 & I 7 & 128 & $3 \cdot 8$ & $5 \cdot 3$ & 5.0 \\
\hline I 8-20 Oct. & 7 & $r_{5}$ & 119 & 3.5 & $4 \cdot 8$ & $4 \cdot 6$ \\
\hline I-3 Nov. & 7 & I9 & I I I & $2 \cdot 9$ & 4.0 & $4 \cdot 3$ \\
\hline 15-17 Nov. & 7 & 19 & 100 & $3 \cdot 1$ & $4 \cdot 3$ & 3.8 \\
\hline 28-30 Nov. & 7 & 21 & 100 & $3 \cdot 7$ & $5 \cdot 2$ & $3 \cdot 8$ \\
\hline 13-I5 Dec. & 7 & 19 & 101 & $2 \cdot 4$ & $3 \cdot 4$ & $3 \cdot 8$ \\
\hline
\end{tabular}


( 144 and $192 \mathrm{~h}$ ) were long enough to give reliable results. The remainder of the values were obtained from periods ranging from 264 to $504 \mathrm{~h}$. Although the latter was unnecessarily long it was thought desirable to use a 3 -day sampling period for the group of seven sheep throughout the experiment. As minor difficulties in the procedure were overcome, this total could have been reduced.
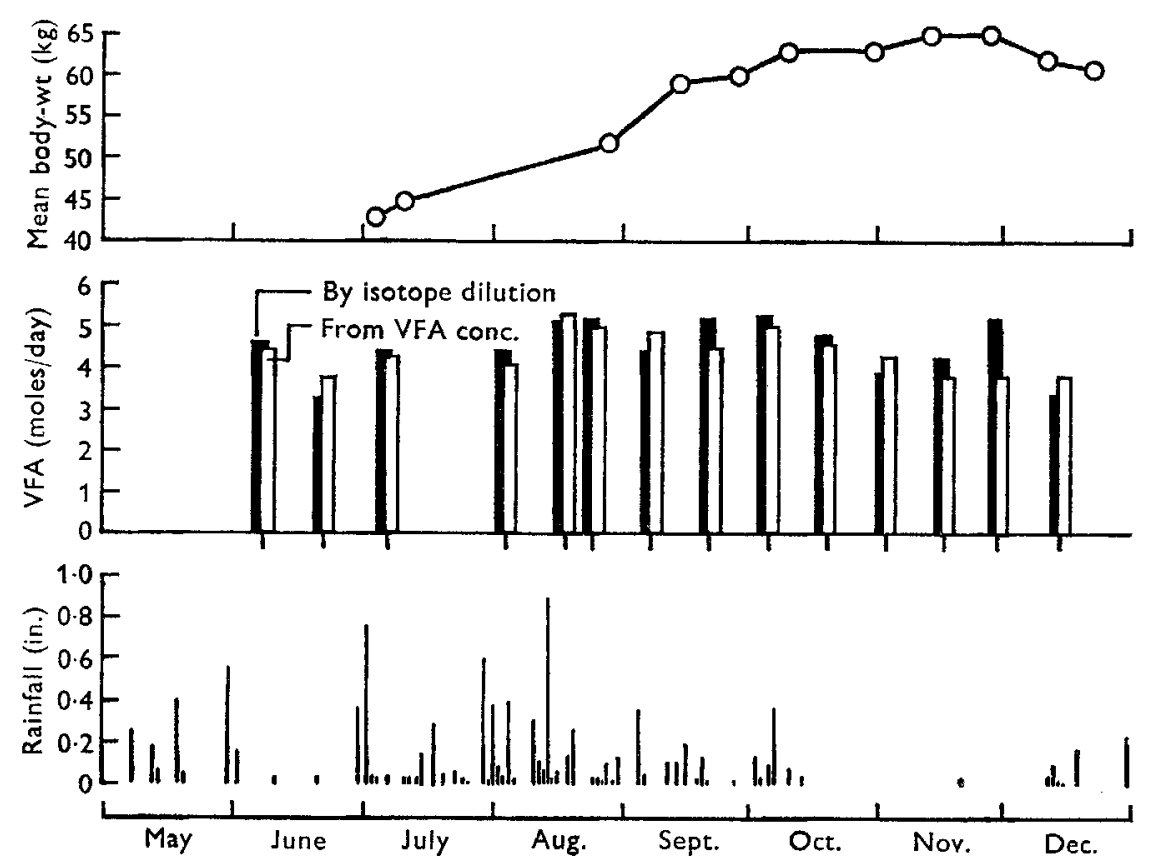

Fig. 4. VFA production in grazing sheep, June-December 1967.

Between July and December mean production rates ranged from 3.4 to 5.3 moles VFA/sheep daily, the general trend showing an increased rate from the middle of August to near the end of October. This corresponds to the good growth of pasture in August following end-of-June rains, and to the drying-off which started in midOctober. At no time was there any shortage of food in the paddock, and so the changes in production rate-a reflection of intake and digestibility-represent the full potential yields, of substances capable of conversion into VFA in the animals, by the pasture during its different stages of growth and decline.

Individual acids in the rumen VFA. The values obtained at intervals during the experimental period showed some progressive but small changes in the composition of the mixture of VFA in the rumen (Table 5), the tendency being towards an increased proportion of propionic and a decreased proportion of acetic acid in the period of good growth of the pasture in September, as compared with the earlier and later periods. For each acid an analysis was made to assess the significance of difference between the five sampling dates. The mean molar proportions quoted in Table 5 have been adjusted to remove the effects of different sheep being represented in them, on the basis of the least squares analysis of the results. 
In the composition of the rumen VFA there were no significant differences between the individual sheep used in the samplings. In the proportions of acetic and propionic acids the differences between sampling dates were significant at the $\mathbf{I} \%$ probability level; in those of butyric acid they were significant at the $5 \%$ level, owing chiefly to a sharp fall in the proportion in the last sample. The values, however, represent periods of only $\mathrm{r}$ or 2 days at each period and may therefore be too few for any firm conclusions.

Weight changes. Body-weights, including wool removed at shearing, are shown in Fig. 4 as means for the group. The weights of the sheep increased steadily during the growing period of the pasture, remained fairly constant in the drying-off period and began to decline only in the last few weeks of the trial. VFA production however, appears to have started to decline somewhat earlier.

Table 5. Composition of rumen VFA in grazing sheep

\begin{tabular}{|c|c|c|c|c|c|}
\hline \multirow[b]{2}{*}{ Date } & \multirow{2}{*}{$\begin{array}{c}\text { No. of } \\
\text { sheep } \\
\text { sampled }\end{array}$} & \multirow{2}{*}{$\begin{array}{l}\text { No. of } \\
\text { determina- } \\
\text { tions }\end{array}$} & \multicolumn{3}{|c|}{ Rumen VFA-mean molar proportion (\%) } \\
\hline & & & Acetic & Propionic & Butyric \\
\hline 8-9 June & 4 & 6 & $64 \cdot 6$ & 19.9 & I 5.5 \\
\hline $2 I-22$ June & 4 & 4 & 63.9 & $22 \cdot 1$ & $14 \%$ \\
\hline 5-7 July & 6 & 6 & $61 \cdot 9$ & $2 r \cdot 9$ & $16 \cdot 2$ \\
\hline 22 Sept. & 7 & 7 & $57 \cdot 9$ & $25 \cdot 4$ & $16 \cdot 7$ \\
\hline 30 Nov. & 6 & 6 & $67 \cdot 8$ & $20 \cdot 1$ & $12 \cdot 2$ \\
\hline & Approxim & te SE of mean & $1 \cdot 70$ & 0.94 & $1 \cdot 00$ \\
\hline
\end{tabular}

\section{Calculation of VFA production from VFA concentrations in the rumen fluid of grazing sheep}

The series of tests made on three sheep (ten pairs of $24 \mathrm{~h}$ composite samples) indicated that, for the rate of flow of dialysing medium employed throughout this work, the mean value for the ratio of VFA in the rumen fluid to VFA in the dialysate was I.I6 (SD $0 \cdot 12)$. This determination makes it possible to apply the relationship previously established between VFA production rate and VFA concentration in the rumen fluid (Fig. 3) to the values obtained during the grazing trial. Production rates calculated from concentrations in this way have been included in Table 4 and are illustrated in Fig. 4. It can be seen that on most occasions the rates so obtained were quite close to those given by the isotope dilution method.

\section{DISCUSSION}

While the isotope dilution method is known to be satisfactory for measuring entry rates of VFA into the rumen when the VFA pool is constant in size, it was necessary to decide whether it could have valid application under conditions where rates of feeding, and therefore pool size of VFA in the rumen, were likely to be irregular within and between days.

It has previously been shown (Gray et al. 1967) that the method could be employed when sheep were fed at $12 \mathrm{~h}$ intervals, the evidence being that with its use similar quantities of VFA were calculated to be produced whether the animals were fed at 
$\mathrm{I} 2 \mathrm{~h}$ intervals, when the pool size varied considerably, or at $\mathrm{I} \mathrm{h}$ intervals, when it was virtually constant. Supporting evidence was provided by trials carried out in a model rumen (Gray et al. 1966).

Although the conditions in that earlier work covered changing pool size they corresponded only to those in sheep fed intermittently, but not irregularly. It was therefore necessary to extend the tests of the validity of the method to conditions corresponding to those likely to be met in the field.

With irregular feeding the amount of fodder passing through the rumen each day or part of a day may be very different from the amount consumed in that time, but as the period examined is increased, the amount consumed and the amount passing through will approach the same value. Even with steady feeding the two values may be different each day (Gray et al. 1967) and so with irregular intake the results for a considerable number of days may need to be examined to be sure that a proper basis is found for comparing yields of VFA per unit weight of fodder fermented.

Results for the sheep fed on roughages showed that by this method similar amounts of VFA were calculated to be produced from unit weight of fodder whether it was fed at steady or irregular rates. Although it is not possible to say that the production of VFA from unit weight of fodder must necessarily be the same under steady and irregular feeding regimes, the fact that good agreement was found for three diets and two different types of irregular feeding lends strong support to the view that the method gives a reasonable measure of production during irregular intake. It should therefore be applicable in studies of VFA production in grazing sheep. A proviso is that mean rates should be determined over a sufficiently long period.

Further evidence for the validity of the method in conditions in which VFA pool size varied was provided by the results of the experiment in the model rumen.

In Tables $\mathrm{I}$ and 2 values for the quotient ${ }^{14} \mathrm{C}$ infused $/{ }^{14} \mathrm{C}$ in VFA' are given for each $24 \mathrm{~h}$ period. When feeding was steady this quotient was known to represent accurately the production of VFA during that time. But when feeding was irregular, and consequently a steady state did not exist in the rumen, there was no direct evidence for the accuracy of the estimate. The accuracy could be checked if the amount of fodder fermented in that time were known, but the amount fermented is not the same as the amount fed in the same period. Thus, though it can be accepted that an accurate value for production from a unit weight of fodder is given by this method after a sufficiently long sampling period during irregular feeding, it could not be expected to show accurately the amounts of acid produced during individual days.

A primary objective in this and earlier work has been to seek a basis for comparisons between fodders or pastures through measurement of their yield of VFA in the rumen. There is a wide variation in and between grazing sheep in the amount and nature of herbage consumed each day and this must lead to differences in daily production of VFA which are not directly related to the quality of the diet. Consequently, if VFA production is to be used as a basis for comparing pastures, treatments of pastures, or treatments of grazing animals, it is necessary to measure average production per day over a sufficient time in a sufficient number of animals.

It had to be decided what sampling period to choose for the grazing trials. Ideally 
this would have been based on the variation in intake between sheep and between days, but such information is not available in precise form. Measurements of time spent grazing, however, suggest that intake would be unlikely to be any more variable than it was in the second type of irregular feeding used in the cage trials. It therefore seems satisfactory to have decided to aim at sampling times totalling ten or more periods of $24 \mathrm{~h}$ each, collecting the samples within a 3 -day period from a group of seven sheep. Such total sampling times should be long enough to indicate a difference between pastures, whether this is due to difference in digestibility, intake, or any property which affects the amount of VFA formed in the rumen.

Thus the mean production rates, ranging from 3.4 to 5.3 moles daily, can be considered to represent changing values of the pasture for the group of sheep used. The rates may of course prove to be affected by the breed, age, state of health, or metabolic activity of the animals used and this would affect any comparison made between the pasture at one and another stage of its growth. This difficulty need not arise, however, in comparing two or more pastures concurrently.

An important aim of the work reported here has been to test the usefulness of the relationship between concentration and production of VFA in the rumen, for calculating production rates as proposed by Leng \& Brett (1966). The relationship was established on the basis of the methods employed throughout the present work so that its use could be tested against the results obtained in the grazing trials. The regression established (Fig. 3) cannot be immediately compared with that arrived at by Leng \& $\operatorname{Brett}(1966)$ because those workers dealt with gross rather than net entry rates of VFA. It can, however, be compared with the regression of Leng $e$ t al. (1968) who dealt with the energy equivalent of the acid formed, and it is clear that the findings have closely similar implications, although their results indicate a somewhat greater slope in the regression of production on concentration than is shown in equation (r) (p. 106).

Both the cage experiments and the grazing trials showed that the relationship (equation (I)) held good under conditions of irregular intake of food.

These findings provide experimental evidence to support the assumption of Leng et al. (1968) that the relationship with concentration in the rumen should prove a satisfactory basis for measuring VFA production in the field. Its use would clearly result in a considerable saving of time. It would, however, appear to be advisable to check the constants in this relationship if different sheep or diets are to be employed. Difficulties in arranging for automatic and continuous (or frequent) sampling of rumen fluid in the field have not yet been overcome, but use of the dialysing probe allows good sampling of the rumen acids to continue automatically throughout the day, and an adjustment can be made to convert the values for VFA concentration in the dialysate into mean VFA concentrations in the rumen fluid.

It is not suggested that use of the relationship should supplant the isotope dilution method in all types of experiment; it is clear from Fig. 3 that there can be wide deviations in the regression stated. In field studies, however, there may also be a special advantage in using the simpler approach. When sheep are at pasture the physical state of the rumen contents can be very different from that found when chaffed dry roughages are fed, and in these circumstances difficulties could possibly 
British Fournal of Nutrition, Vol. 23, No. I

Plate I

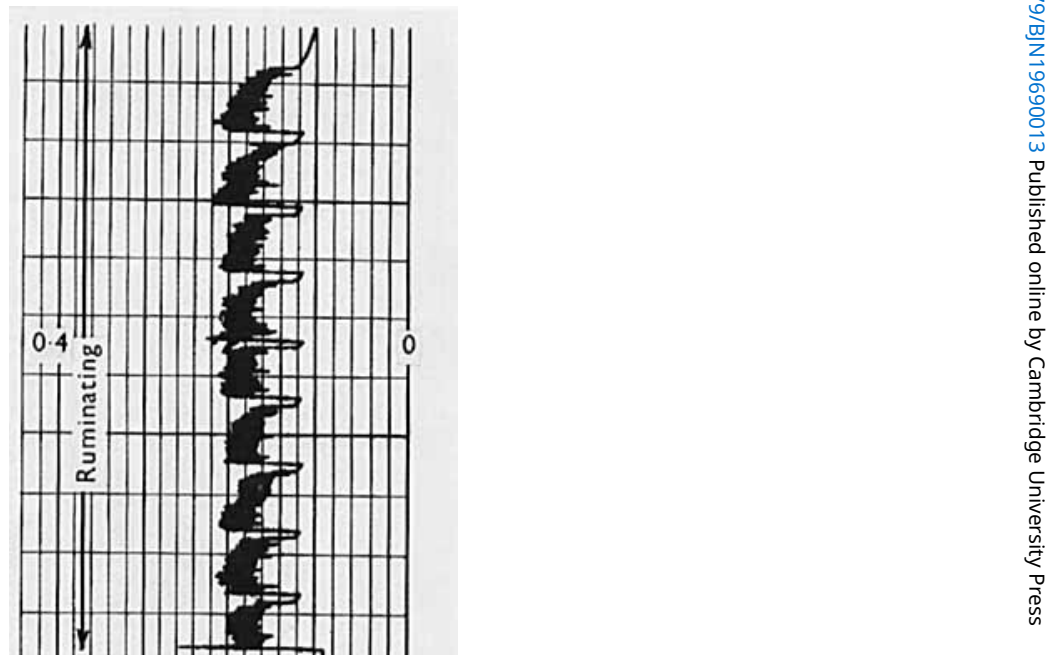

R. A. WELLER, A. F. PILGRIM AND F. V. GRAY

(Facing p. I I x) 
arise through a less thorough mixing of the infused marker with the rumen acids. Some indication of this was found during the present work and experiments are being planned to examine the question further.

We are indebted to $\mathrm{Mr} \mathrm{N}$. Buckley for assistance in the field work, to $\mathrm{Mr} \mathrm{V}$. A. Stephen for arranging the telemetry of grazing and to $\mathrm{Mr} \mathrm{G}$. B. Belling for the atomic absorption analyses. We also wish to thank Mr W. B. Hall of the Division of Mathematical Statistics, CSIRO, for analysis of the results where needed.

\section{REFERENCES}

Bergman, E. N., Reid, R. S., Murray, M. G., Brockway, J. M. \& Whitelaw, F. G. (1965). Biochem. F. 97, 53 .

Gray, F. V., Weller, R. A., Pilgrim, A. F. \& Jones, G. B. (1966). Aust. F. agric. Res. 17, 69.

Gray, F. V., Weller, R. A., Pilgrim, A. F. \& Jones, G. B. (1967). Aust. Y. agric. Res, 18, 625.

Leng, R. A. \& Brett, D. J. (1966). Br. F. Nutr. 20, 54 I.

Leng, R. A., Corbett, J. L. \& Brett, D. J. (1968). Br. F. Nutr. 22, 57.

Leng, R. A. \& Leonard, G. J. (1965). Br. Y. Nutr. 19, 469.

Weller, R. A., Gray, F. V., Pilgrim, A. F. \& Jones, G. B. (1967). Aust. F. agric. Res. 18, 107.

\section{EXPLANATION OF PLATE}

Telemetric record of jaw movements of a sheep while grazing, resting and ruminating. 